\title{
Correction to: Quality of Health Care
}

Marcia A. Testa

\section{Correction to: A. Veves et al. (eds.), The Diabetic Foot, Contemporary Diabetes,} https://doi.org/10.1007/978-3-319-89869-8

The below mentioned reference was missing in the chapter 25 .

Edmonds ME, Blundell MP, Morris ME, Thomas EM, Cotton LT, Watkins PJ. Improved survival of the diabetic foot: the role of a specialized foot clinic. Q J Med. 1986;60(232):763-71

Now this has been included in the references list and the citation and the references were renumbered consecutively and also moved reference Lorig (2001) from 74 to 86 in the references list.

The updated online version of this chapter can be found at https://doi.org/10.1007/978-3-319-89869-8_25 